\title{
Peranan Kelekatan Aman Pada Ayah dan Ibu Terhadap Penyesuaian Diri Santriwati
}

\author{
Risnida Muzdalifah \\ Psikologi, Universitas Airlangga, Indonesia \\ Email : risnida.muzdalifah@gmail.com \\ Hemy Heryati Anward \\ Psikologi, Universitas Airlangga, Indonesia \\ Email: hemy@gmail.com \\ Dwi Nur Rachmah \\ Psikologi, Universitas Airlangga, Indonesia \\ Email: dwi_nurrachmah@yahoo.co.id
}

(Diterima: 14-September-2018; direvisi: 10-Februari-2019; dipublikasikan: 28-Juni-2019)

\begin{abstract}
Abstrak. Penelitian ini bertujuan untuk mengetahui apakah terdapat peranan kelekatan aman pada ayah dan ibu terhadap penyesuaian diri. Metode pengumpulan data menggunakan skala psikologi meliputi skala kelekatan aman pada ayah, skala kelekatan aman pada ibu dan skala penyesuaian diri. Skala ini menggunakan skala model Likert dan analisis data pada penelitian ini dilakukan dengan analisis regresi linier berganda. Hasil penelitian menunjukkan ada peranan kelekatan aman pada ibu dan ayah terhadap penyesuaian diri santriwati dan tidak terdapat perbedaan antara kelekatan aman pada ayah dan ibu terhadap penyesuaian diri santriwati. Berdasarkan hasil penelitian tersebut, sumbangan efektif kelekatan aman pada ayah dan ibu terhadap penyesuaian diri sebesar $20,5 \%$ sedangkan $79,5 \%$ sisanya sumbangan dari faktor lain selain kelekatan aman pada ayah dan ibu.
\end{abstract}

Kata kunci: kelekatan aman; ayah; ibu; penyesuaian diri; santriwati.

\begin{abstract}
The purpose of this study was to find out whether there was a role of secure attachment to father and mother towards self-adjustment. The subjects in this study were 60 people, which were selected using a cluster random sampling technique. Data were collected using psychological scales including a scale of secure attachment to father, a scale of secure attachment to mother and a scale of self-adjustment. These scales used Likert-Scale model and data were analyzed using multiple linear regression analysis. The results showed there was a role for safe attachment of mothers and fathers to female students 'adjustment and there was no difference between the safe attachment of fathers and mothers to female students' adjustment. Based on these results, it can be seen that the effective contribution of the secure attachment to father and mother towards the self-adjustment was $20.5 \%$, while the remaining $79.5 \%$ was contributed by other factors.
\end{abstract}

Keywords: secure attachment; father; mother; adjustment; santriwati. 


\section{PENDAHULUAN}

Salah satu lembaga pendidikan formal berbasis agama Islam di Indonesia adalah pesantren. Pesantren merupakan asrama dan tempat santri belajar agama serta mengaji. Pesantren mengharuskan santri untuk tinggal di asrama yang mewajibkan mereka untuk menaati peraturan yang ada. Para santri harus belajar untuk mandiri dan mengikuti jadwal yang rutin sejak bangun tidur sampai malam hari. Ketentuan ini tentu mengharuskan para santri untuk menyesuaikan diri.

Ownsworth (2010) menyatakan penyesuaian diri adalah proses kehidupan untuk dapat menciptakan keharmonisan dengan diri sendiri, orang lain, dan lingkungan dengan perubahanperubahan yang terjadi pada diri individu. Perubahan tempat tinggal bagi remaja dapat menjadi sebuah awal dari munculnya berbagai permasalahan. Begitupula ketika remaja tinggal di pesantren yang mengharuskannya berpisah dari orangtua.

Masalah yang dapat terjadi pada para santri yang harus tinggal di asrama adalah tidak mampu menyesuaikan diri dengan kehidupan sistem asrama. Menurut Hidayat (2012) setiap hari santri dibebani oleh kegiatan-kegiatan yang tidak ringan, mulai dari bangun tidur hingga tidur kembali diatur sedemikian rupa sehingga tidak ada waktu yang terbuang dengan percuma kemudian menjadi masalah adalah santri yang tidak mampu menyesuaikan diri dengan kehidupan system asrama tersebut. Begitu pula hasil penelitian Lisnawati dan Susandari (2015) menunjukkan bahwa dari seluruh santriwati kelas VIII TMI tersebut 54\% santriwatinya melakukan pelanggaran seperti membolos sekolah, tidak berbahasa Arab/Inggris di lingkungan pesantren, bahkan keluar dari pondok pesantren tanpa izin (kabur).

Perubahan tempat tinggal yang mengharuskan anak berpisah dari orangtua merupakan transisi yang signifikan untuk remaja (Thurber dan Walton, 2012). Salah satu faktor yang mempunyai peranan terhadap penyesuaian diri adalah keadaan lingkungan yang salah satunya adalah lingkungan keluarga. Lingkungan keluarga merupakan media sosial pertama yang dijalani anak. Orangtua yang menerima anak dengan baik, akan menciptakan suasana hangat, menyenangkan, dan rasa aman bagi anak (Gunarsa dan Gunarsa, 2008). Perasaan aman tersebut didapat remaja melalui kelekatan aman dengan ayah dan ibunya. Hasil penelitian Azic,
Dorcic dan Juretic (2015) menemukan bahwa kelekatan memiliki peranan terhadap penyesuian diri dengan sumbangan efektif sebesar $28 \%$. Begitu pula hasil penelitian Al-Yagon (2011) yang menunjukkan bahwa sebanyak 53\% dari subjek penelitian memiliki kelekatan yang aman dengan orangtuanya membuat subjek lebih sedikit mengalami kesulitan dalam hal sosioemosional ketika harus menyesuaikan diri. Dari dua penelitian tersebut, dapat diasumsikan bahwa remaja yang memiliki cukup kelekatan aman dengan orangtua maka penyesuaian dirinya di lingkungan baru akan baik.

Kelekatan adalah ikatan timbal balik yang bertahan antara dua orang terutama bayi dan figur lekatnya yang masing-masing berkontribusi kepada kualitas hubungan (Papalia, 2014). Kelekatan akan mempengaruhi anak ketika memasuki masa remaja sampai dewasa (Mattanah, Govern, dan Lovez, 2011). Hal ini disebabkan karena kelekatan memiliki fungsi adaptif untuk menyediakan dasar rasa aman sehingga dapat membantu remaja terhindar dari kecemasan dan kemungkinan perasaan tertekan dalam menyesuaikan diri dengan berbagai perubahan yang terjadi (Santrock, 2011).

Remaja memiliki kelekatan yang berbeda dengan ibu dan ayah. Ayah akan memberikan pengaruh yang berbeda kepada remaja dalam hal hubungan anak dengan teman sebayanya (Krisnatuti dan Putri, 2012). Apabila remaja lekat dengan ayah maka akan cenderung memiliki kemandirian dan otonomi untuk berada di luar lingkungan keluarganya. Mereka akan mudah dalam menyesuaikan diri apabila tinggal jauh dari orangtua karena remaja mudah menjalin hubungan dengan teman-teman sebayanya dan memiliki kemandirian untuk tinggal di lingkungan yang baru (Laumi dan Adiyanti, 2012).

Peran sosial ibu di dalam keluarga yaitu cenderung mengurus hubungan mereka dengan anak-anak sehingga mempengaruhi sebagian besar kondisi psikologis anak. Remaja yang lekat dengan ibunya akan memberikan rasa aman dan kondisi psikologis remaja tidak mudah terguncang oleh hal-hal baru yang ditemuinya di luar lingkungan keluarga. Remaja tetap akan merasa aman apabila berada di lingkungan baru yang jauh dari orangtuanya. Mereka akan mudah untuk menyesuaikan diri di lingkungan baru tanpa merasa stress dan depresi (Laumi dan Adiyanti, 2012).

Adanya santriwati yang tidak betah karena terbiasa melakukan semuanya dengan dibantu 
oleh ibu. Ada juga santriwati yang lebih sering menghabiskan waktu dengan ayahnya, sehingga merasa kesepian ketika harus hidup terpisah. Namun beberapa santriwati lain, yang juga dekat dengan orangtuanya, dapat menyesuaikan diri dengan cepat. Mereka masuk ke pesantren atas keputusannya sendiri, serta merasa aman karena masih dapat bertemu dengan orangtuanya ketika akhir pekan. Meskipun begitu, ada santri yang merasa berat dengan peraturan yang ada. Seperti tidak diperbolehkan memiliki telepon seluler, tidak setiap hari dapat bertemu dan berkomunikasi dengan orangtua, serta diharuskan untuk melakukan kegiatan sehari-hari sendiri. Selain itu, tidak berani mencari teman baru ketika awal masuk pesantren membuat santri menjadi tidak betah. Mereka melakukan pelanggaran agar dihukum dan dikeluarkan dari pesantren tersebut.

Sesuai pembahasan sebelumnya, maka peneliti tertarik untuk melakukan penelitian tentang peranan kelekatan aman pada ayah dan ibu terhadap penyesuaian diri santriwati SMP Pondok Pesantren Modern Puteri An-Najah Cindai Alus Martapura.

Adapun hipotesis dalam penelitian ini adalah terdapat peranan kelekatan aman pada ayah dan ibu terhadap penyesuaian diri santriwati serta tidak terdapat perbedaan antara kelekatan aman pada ayah dan ibu terhadap penyesuaian diri santriwati SMP Pondok Pesantren Modern Puteri An-Najah Cindai Alus Martapura.

\section{METODE}

Subjek dalam penelitian ini adalah santriwati yang berjumlah 60 orang. Pengambilan sampel menggunakan teknik cluster random sampling, yaitu pengambilan sampel secara acak terhadap unit (individu), di mana sampling unitnya berada dalam satu kelompok (cluster). Adapun skala yang digunakan adalah skala kelekatan aman pada ibu, skala kelekatan aman pada ayah, dan skala penyesuaian diri.

Skala kelekatan aman pada ayah dan ibu disusun berdasarkan dimensi yang dikemukakan oleh Armsden dan Greenberg (2009) untuk mengukur skala attachment mengacu pada 3 dimensi yaitu komunikasi, kepercayaan, dan keterasingan. Skala penyesuaian diri disusun berdasarkan indikator yang dikemukakan oleh Desmita (2012), Schneiders (2008) dan Runyon dan Haber (Warsito dan Warsito, 2013), yaitu meliputi aspek kematangan intelektual, kematangan emosional, kematangan sosial, selfimage positif, dan kemampuan untuk belajar serta memanfaatkan pengalaman masa lalu. Adapun teknik analisis data yang digunakan dalam penelitian ini adalah analisis regresi linier berganda.

\section{HASIL DAN PEMBAHASAN}

Pengambilan data penelitian dilakukan pada tanggal 23 Maret 2016. Penelitian dilaksanakan di SMP Pondok Pesantren Modern

Puteri An-Najah Cindai Alus Martapura. Proses pengambilan data penelitian dilakukan secara langsung oleh peneliti. Cara skoring skala penelitian dilakukan dengan menentukan nilai tertinggi pada masing-masing pernyataan favourable yaitu nilai 4 untuk respon sangat setuju dan nilai 4 untuk respon jawaban sangat tidak setuju pada pernyataan unfavourable.

Berikut kategorisasi data penelitian variabel kelekatan aman pada ibu:

Tabel 1. Distribusi Kategorisasi Data Variabel Kelekatan Aman pada Ibu

\begin{tabular}{ccccc}
\hline Variabel & Rentang nilai & Kategori & Frekuensi & Persentase \\
\hline kelekatan aman pada ibu & $X<62$ & Rendah & - & - \\
& $62 \leq X<93$ & Sedang & 50 & $83,33 \%$ \\
& $93 \leq X$ & Tinggi & 10 & $16,67 \%$ \\
\hline
\end{tabular}

Hasil kategorisasi table 1 subjek terhadap respon skala kelekatan aman pada ibu menunjukkan tidak ada subjek yang merespon skala kelekatan aman pada ibu dalam kategori rendah, sedangkan sebanyak 50 subjek $(83,33 \%)$ memiliki kelekatan aman pada ibu dalam kategori sedang, dan sebanyak 10 subjek $(16,67 \%)$ memiliki kelekatan aman pada ibu dalam kategori tinggi. Hal ini menunjukkan bahwa santriwati SMP Pondok Pesantren Modern Puteri An-Najah Cindai Alus Martap`ura memiliki kelekatan aman yang sedang pada ibu. 
Santriwati dengan kategori sedang dalam kelekatan aman pada ibu memiliki kemampuan untuk menyesuaikan diri dengan cukup baik tetapi kelekatan yang terjalin antara santriwati dengan ibu tidak sebaik santriwati dengan kategori tinggi. Santriwati jarang memberitahukan bagaimana perkembangannya selama di pesantren kepada ibunya dan sudah terbiasa tidak bertemu dengan ibunya. Barrocas
(2009) hal ini akan terjadi pada anak memiliki pengalaman-pengalaman yang positif sebelumnya yang berhubungan dengan terbentuknya kepercayaan, sehingga anak menjadikan pengalaman sebagai contoh dalam membangun hubungan selanjutnya.

Berikut kategorisasi data penelitian variabel kelekatan aman pada ayah :

Tabel 2. Distribusi Kategorisasi Data Variabel Kelekatan Aman pada Ayah

\begin{tabular}{ccccc}
\hline Variabel & Rentang nilai & Kategori & Frekuensi & Persentase \\
\hline Kelekatan aman & $X<72$ & Rendah & 3 & $5 \%$ \\
pada ayah & $72 \leq X<108$ & Sedang & 29 & $48,33 \%$ \\
& $108 \leq X$ & Tinggi & 28 & $46,67 \%$ \\
\hline
\end{tabular}

Hasil kategorisasi table 2 subjek terhadap respon skala kelekatan aman pada ayah menunjukkan sebanyak 3 subjek (5\%) memiliki kelekatan aman pada ayah dalam kategori rendah, sedangkan sebanyak 29 subjek $(48,33 \%)$ memiliki kelekatan aman pada ayah dalam kategori sedang, dan sebanyak 28 subjek $(46,67 \%)$ memiliki kelekatan aman pada ayah dalam kategori tinggi. Hal ini menunjukkan bahwa santriwati SMP Pondok Pesantren Modern Puteri An-Najah Cindai Alus Martapura memiliki kelekatan aman yang sedang pada ayah. Santriwati dengan kategori sedang dalam kelekatan aman pada ayah memiliki kemampuan untuk menyesuaikan diri dengan cukup baik tetapi kelekatan yang terjalin antara santriwati dengan ayah tidak sebaik santriwati dengan kategori tinggi. Santriwati jarang menghubungi ayahnya selama di pesantren dan tidak terbiasa menceritakan masalah dengan ayahnya. Hal ini sesuai dengan Barrocas (2009) yaitu anak yang di asuh dan dibesarkan dengan komunikasi yang baik akan tumbuh menjadi individu yang mampu berkomunikasi dengan baik dan lebih terbuka untuk mengungkapkan apa yang dipikirkan dan apa yang dirasakan.

Verschueren dan Marcoen (Al-Yagon, 2011) menyebutkan bahwa kelekatan aman pada ayah dapat membantu anak menyesuaikan diri dengan cara diterima lebih baik di lingkungan sosialnya. Sedangkan kelekatan aman pada ibu dapat membantu anak menyesuaikan diri dengan cara lebih mudah memiliki kelompok teman sebaya di lingkungan sosialnya. Berdasarkan kategorisasi kelekatan aman pada ayah, terdapat 3 santriwati (5\%) berada dalam kategori rendah sedangkan tidak terdapat kelekatan aman pada ibu dengan kategori rendah sehingga penyesuaian dirinya menjadi kurang baik. Hal ini sejalan dengan penelitian Liebermen (dalam AlYagon, 2011) yang menyebutkan bahwa ketika anak memasuki masa remaja hubungan antara anak perempuan dengan ayah dapat berubah menjadi lebih datar dan anak lebih banyak bercerita dengan ibunya. Sehingga kelekatan yang terjalin antara anak dengan ibu lebih tinggi dibandingkan dengan ayah.

Tabel 3. Distribusi Kategorisasi Data Variabel Penyesuaian Diri

\begin{tabular}{ccccc}
\hline Variabel & Rentang nilai & Kategori & Frekuensi & Persentase \\
\hline Penyesuaian diri & $\mathrm{X}<104$ & Rendah & - & - \\
& $104 \leq \mathrm{X}<156$ & Sedang & 35 & $58,33 \%$ \\
& $156 \leq \mathrm{X}$ & Tinggi & 25 & $41,67 \%$ \\
\hline
\end{tabular}

Hasil kategorisasi sujek terhadap respon skala penyesuaian diri menunjukkan tidak ada subjek yang merespon skala penyesuaian diri dalam kategori rendah, sedangkan sebanyak 35 subjek $(58,33 \%)$ memiliki kemampuan penyesuaian diri dalam kategori sedang, dan sebanyak 25 subjek $(41,67 \%)$ memiliki kemampuan penyesuaian diri dalam kategori tinggi. Hal ini menunjukkan bahwa santriwati SMP Pondok Pesantren Modern Puteri An-Najah 
Cindai Alus Martapura memiliki penyesuaian diri yang cukup baik. Sejalan dengan hasil penelitian Indrawati dan Fauziah (2012) yang menyatakan bahwa hubungan orang tua dengan anaknya dapat mempengaruhi individu dalam melakukan penyesuaian diri karena penerimaan orangtua terhadap anak akan menumbuhkan rasa aman, percaya diri, penghargaan, sehingga terjadi penyesuaian diri yang baik sehingga semakin baik kelekatan aman yang terbentuk antara remaja dan orangtua semakin baik pula penyesuaian diri yang dimiliki remaja.

Tabel 4. Hasil Uji Normalitas, Uji Linearitas, dan Uji Heteroskedastisitas Variabel Kelekatan Aman pada Ayah dan Ibu dengan Penyesuaian Diri

\begin{tabular}{lccc}
\hline \multicolumn{1}{c}{ Variabel } & $\begin{array}{c}\text { Uji } \\
\text { Normalitas }\end{array}$ & $\begin{array}{c}\text { Uji } \\
\text { Linearitas }\end{array}$ & $\begin{array}{c}\text { Uji } \\
\text { Heteroskedas }\end{array}$ \\
\hline Kelekatan Aman pada Ibu & Normal & Linear & Tidak ada \\
& $(\mathrm{p}=0,098)$ & $(\mathrm{p}=0,005)$ & $\begin{array}{c}\text { masalah } \\
(\mathrm{p}=0,816)\end{array}$ \\
& Normal & Linear & Tidak ada \\
masalah \\
Kelekatan Aman pada Ayah & $(\mathrm{p}=0,054)$ & $(\mathrm{p}=0,036)$ & $(\mathrm{p}=0,754)$ \\
& & & - \\
Penyesuaian Diri & Normal & - & \\
& $(\mathrm{p}=0,200)$ & & \\
\hline
\end{tabular}

Berdasarkan uji normalitas nilai signifikansi untuk skala kelekatan aman pada ibu sebesar 0,098 $(>0,05)$, nilai signifikansi untuk skala kelekatan aman pada ayah sebesar 0,054 $(>0,05)$, sedangkan nilai signifikansi untuk skala penyesuaian diri sebesar $0,200(>0,05)$. Maka dapat disimpulkan bahwa data skala kelekatan aman pada ayah dan ibu serta penyesuaian diri berdistribusi normal.

Pada uji linearitas nilai signifikansi didapatkan sebesar 0,005 $(<0,05)$ untuk skala kelekatan aman pada ibu dan $0,036(<0,05)$ untuk skala kelekatan aman pada ayah. Maka, dapat disimpulkan bahwa terdapat hubungan yang linier antara variabel kelekatan aman pada ayah dan ibu dengan penyesuaian diri.

Berdasarkan uji heteroskedastisitas nilai signifikansi untuk skala skala kelekatan aman pada ibu sebesar 0,816 $(>0,05)$, nilai signifikansi untuk skala kelekatan aman pada ayah sebesar 0 , $754(>0,05)$. Maka dapat disimpulkan tidak terdapat masalah heteroskedastisitas dalam semua data penelitian.

Tabel 5. Hasil Uji Regresi Linier Berganda Variabel Kelekatan Aman pada Ayah dan Ibu dengan Penyesuaian Diri

\begin{tabular}{lcccccc}
\hline \multicolumn{1}{c}{ Variabel } & $\begin{array}{c}\mathbf{T} \\
\text { Hitung }\end{array}$ & $\begin{array}{c}\mathbf{T} \\
\text { tabel }\end{array}$ & F hitung & $\begin{array}{c}\mathbf{F} \\
\text { tabel }\end{array}$ & $\mathbf{R}$ & $\mathbf{R}^{\mathbf{2}}$ \\
\hline Kelekatan aman pada ibu & 3,046 & 2,002 & 7,330 & 3,159 & 0,452 & 0,205 \\
Kelekatan aman pada ayah & 2,319 & 2,002 & 7,330 & 3,159 & 0,452 & 0,205 \\
\hline
\end{tabular}

Berdasarkan hasil analisis data penelitian dalam uji regresi linier berganda, maka tiga hipotesis yang diajukan dapat diterima. Hasil analisis untuk hipotesis pertama dinyatakan diterima. Sebagaimana ditunjukkan oleh nilai $\mathrm{t}$ hitung > t tabel $(2,319>2,002)$. Sementara itu, nilai koefisien regresi kelekatan aman pada ibu sebesar 0,412. Nilai koefisien regresi positif tersebut menunjukkan terdapat hubungan searah antara kelekatan aman pada ibu dengan penyesuaian diri, artinya semakin tinggi kelekatan aman pada ibu maka semakin tinggi pula penyesuaian diri santriwati SMP Pondok
Pesantren Modern Puteri An-Najah Cindai Alus Martapura begitupula sebaliknya. Hasil penelitian ini diperkuat oleh penelitian Al-Yagon (2011) yang menyatakan bahwa ada peranan kelekatan aman terhadap penyesuaian diri individu. Sebanyak 53\% dari subjek penelitian memiliki kelekatan yang aman dengan ibunya akan mengurangi kesulitan anak terutama dalam hal sosioemosional ketika harus menyesuaikan diri.

Hasil analisis untuk hipotesis kedua dinyatakan diterima. Sebagaimana ditunjukkan oleh nilai $\mathrm{t}$ hitung $>\mathrm{t}$ tabel $(2,319>2,002)$. 
Sementara itu, nilai koefisien regresi kelekatan aman pada ibu sebesar 0,135 . Nilai koefisien regresi positif tersebut menunjukkan terdapat hubungan searah antara kelekatan aman pada ayah dengan penyesuaian diri, artinya semakin tinggi kelekatan aman pada ayah maka semakin tinggi pula penyesuaian diri santriwati SMP Pondok Pesantren Modern Puteri An-Najah Cindai Alus Martapura begitupula sebaliknya. Hasil penelitian ini diperkuat oleh penelitian Verschueren dan Grossman (Al-Yagon, 2011) yang menyatakan bahwa remaja yang lekat dengan ayah maka akan membantu remaja diterima di lingkungan sosial yang baru dan membantunya berani di luar lingkungan keluarganya.

Menurut Scheniders (2008) salah satu faktor yang mempunyai peranan terhadap penyesuaian diri adalah adalah lingkungan keluarga. Lingkungan keluarga merupakan media sosial pertama yang dijalani anak. Orangtua yang menerima anak dengan baik, akan menciptakan suasana hangat, menyenangkan, dan rasa aman bagi anak. Perasaan aman tersebut didapat remaja melalui kelekatan aman dengan ayah dan ibunya. Santrock (2011) menyatakan bahwa kelekatan aman yang terbentuk antara ayah dan ibu dengan anaknya akan memberikan fungsi adaptif sebagai dasar rasa aman agar anak dapat mengeksplorasi dan menguasai lingkungan baru. Selain itu Papalia dan Feldman (2014) serta Levine dan Munsch (2011) menyatakan bahwa kelekatan aman membuat anak lebih baik dalam menyesuaikan diri di lingkungan yang baru.

Hasil analisis untuk hipotesis ketiga yang dinyatakan diterima. Sebagaimana ditunjukkan oleh nilai $\mathrm{F}$ hitung > F tabel $(7,330>3,159)$, artinya kelekatan aman pada ayah dan ibu secara bersama-sama berperan terhadap penyesuaian diri santriwati SMP Pondok Pesantren Modern Puteri An-Najah Cindai Alus Martapura..Hasil penelitian ini diperkuat dengan hasil penelitian Azic, Dorcic dan Juretic (2015) dan Garriot, Love, Tyler, dan Thomas (2010) yang menyatakan bahwa kelekatan aman antara remaja dengan ayah dan ibunya membuat penyesuaian diri remaja baik ketika memasuki masa sekolah. Hubungan yang positif antara remaja dengan ayah dan ibunya membuat penyesuaian akademik, sosial, dan psikologis remaja menjadi lebih baik di lingkungan yang baru.

Berdasarkan perhitungan koefisien determinasi $\left(\mathrm{R}^{2}\right)$ yang diperoleh sebesar 0,205 menunjukkan peranan efektif yang diberikan oleh variabel kelekatan aman pada ayah dan ibu terhadap penyesuaian diri yaitu sebesar $20,5 \%$. Temuan ini menunjukkan bahwa kelekatan aman yang dimiliki santriwati pada ayah dan ibunya merupakan salah satu faktor yang memiliki peranan terhadap penyesuaian diri. sementara 79,5\% lainnya kemungkinan dari variabel lain yang tidak diteliti dalam penelitian ini seperti halnya faktor-faktor yang mempengaruhi penyesuaian diri menurut Schneiders (2008) yaitu keadaan fisik, perkembangan dan kematangan, keadaan psikologis, dan tingkat teligiusitas serta kebudayaan.

\section{SIMPULAN DAN SARAN}

Berdasarkan hasil penelitian tentang peranan kelekatan aman pada ayah dan ibu terhadap penyesuaian diri santriwati SMP Pondok Pesantren Modern Puteri An-Najah Cindai Alus Martapura menunjukkan ada peranan antara kelekatan aman pada ayah dan ibu dengan penyesuaian diri santriwati. Hal ini diperoleh dari nilai $\mathrm{t}$ hitung $>\mathrm{t}$ tabel $(2,319>$ 2,002). Artinya, semakin tinggi kelekatan aman pada ibu maka semakin tinggi pula penyesuaian diri santriwati SMP Pondok Pesantren Modern Puteri An-Najah Cindai Alus Martapura, begitupula sebaliknya.

Sementara itu, nilai t hitung $>\mathrm{t}$ tabel $(2,319$ $>2,002$ ). Artinya semakin tinggi kelekatan aman pada ayah maka semakin tinggi pula penyesuaian diri santriwati SMP Pondok Pesantren Modern Puteri An-Najah Cindai Alus Martapura begitupula sebaliknya

Kemudian diperoleh nilai nilai $\mathrm{F}$ hitung $>$ F tabel $(7,330>3,159)$, artinya tidak ada perbedaan antara peranan kelekatan aman pada ayah dan ibu terhadap penyesuaian diri santriwati SMP Pondok Pesantren Modern Puteri An-Najah Cindai Alus Martapura. Nilai $\mathrm{R}$ yang diperoleh dalam penelitian ini adalah 0,452 , menunjukkan bahwa terjadi hubungan dengan kategori sedang antara kelekatan aman pada ayah dan ibu terhadap penyesuaian diri santriwati SMP Pondok Pesantren Modern Puteri An-Najah Cindai Alus Martapura.

Sumbangan efektif kelekatan aman pada ayah dan ibu terhadap penyesuaian diri sebesar 20,5\%. Sedangkan 79,5\% sisanya adalah dari variabel-variabel lain yang tidak diteliti pada penelitian ini. Sehingga dapat disimpulkan bahwa kelekatan aman pada ayah dan ibu bukan merupakan satu-satunya faktor yang memiliki peranan terhadap penyesuaian diri santriwati 
SMP Pondok Pesantren Modern Puteri An-Najah Cindai Alus Martapura.

Adapun saran yang sesuai dengan penelitian ini antara lain adalah Bagi santriwati SMP Pondok Pesantren Modern Puteri An-Najah Cindai Alus Martapura sebaiknya dapat meningkatkan kelekatan aman dengan ayah dan ibunya dengan cara terus menjaga komunikasi meskipun tinggal jauh dengan ayah dan ibunya, menceritakan masalah ataupun perkembangan yang terjadi dengan dirinya selama di pesantren, dan tidak menolak ketika dikunjungi oleh ayah dan ibunya di pesantren.

Bagi orangtua diharapkan untuk meningkatkan kelekatan yang terjalin antara orangtua dan anak dengan cara mengetahui perkembangan dan peka dengan apa yang terjadi dengan anak, memberikan kasih sayang kepada anak, sering mengunjungi anak di pesantren ataupun rutin menghubungi anak di pesantren. Selain itu, orangtua diharapkan saling mendukung satu dengan yang lainnya agar kelekatan yang terjalin antara orangtua dan anaknya tetap aman karena kelekatan aman pada ayah dan ibu sama-sama berperan dalam penyesuaian diri anak.

Bagi guru dan pihak sekolah diharapkan dapat membantu penyesuaian diri santriwati yang baru masuk dengan cara tidak membatasi komunikasi dan pertemuan antara santriwati dengan orangtuanya sehingga santriwati baru tidak merasa stres ketika harus berpisah dari orangtuanya dan memasuki lingkungan yang baru.

Bagi peneliti selanjutnya hendaknya memperbanyak penelitian yang berfokus pada kelekatan aman pada ayah. Selain itu juga meneliti faktor - faktor lain yang berhubungan dengan penyesuaian diri seperti keadaan fisik, perkembangan dan kematangan, keadaan psikologis, dan tingkat religiusitas serta kebudayaan.

\section{DAFTAR RUJUKAN}

Al-Yagon, M. (2011). Adolescents' subtypes of attachment security with fathers and mothers and self-perceptions of socioemotional adjustment. Scientic Research, 2(4), 291-299. DOI: 10.4236/ psych. 2011.24046.

Azic, S.S. Dorcic, M \& Juretic. (2015). Contribution of parental attachment and involment to the academic, emotional, and social adjustment to college : A three-year longitudinal study. Scientific Empirical Article, 24, 21-32. ISSN: 2350-514.

Barrocas, A.L. (2009). Adolescent attachment to parents and peers. Journal the Emory Center for Myth and Ritual in American Life, 50, 1-28.

Desmita. (2012). Psikologi perkembangan peserta didik. Bandung : PT. Remaja Rosdakarya.

Garriot, P.O. Love. K.M. Tyler, K.M. \& Thomas, D.M. (2010). Testing an attachment model of latina/o college students' psychological adjustment. Hispanic Journal of Behavioral Sciences, 32 (1), 104-117.

DOI: 10.1177/0739986309355753.

Gunarsa, S \& Gunarsa, Y.S. (2008). Psikologi perkembangan anak dan remaja. Jakarta: Gunung Mulia.

Hidayat, D.A.J. (2012). Perbedaan penyesuaian diri santri di pondok pesantren tradisional dan modern. Talenta Psikologi, 1 (2), 106 - 126.

Holmes, J. (2014). John bowlby and attachment theory. New York: Taylor and Francis eLibrary

Indrawati,E.S.\& Fauziah, N. (2012). Attachment dan penyesuaian diri dalam perkawinan. Jurnal Psikologi Undip, 11 (1), 40-49.

Krisnatuti, D \& Putri, H.A. (2012. Gaya pengasuhan orangtua, interaksi serta kelekatan ayah-remaja, dan kepuasan ayah. Jurnal Ilmu Keluarga dan Konsumen, 5, 101-109. ISSN : 19076037.

Laumi \& Adiyanti, M.G. (2012). Attachment of late adolescent to mother, father, and peer, with family structure as moderating variable and their relationships with selfesteem. Jurnal Psikologi, 39, 129 - 142.

Levine, L.E. \& Munsch. J. (2011). Child development an active learning 
approach. Canada : SAGE Publications, Inc

Lisnawati, A \& Susandari. (2015). Hubungan antara persepsi terhadap iklim sekolah dengan penyesuaian sosial santri putri tsanawiyah ponpes al basyariyah bandung yang melakukan pelanggaran. Prosiding Psikologi, 2, 446-45. ISSN: 2460-6448.

Mattanah, J.F., Lopez, F.G., \& Govern. J.M. (2011). The contributions of parental attachment bonds to college student development and adjustment: a metaanalytic review. Journal of Counseling Psychology, 1, 1-32. DOI: 10.1037/ a0024635.

Ownsworth, T. (2010). Adjustment. International Encyclopedia of Rehabilitation. New York : The State University New York.

Papalia, D.E. \& Feldman, R.D. (2014). Menyelami perkembangan manusia edisi 12 (terjemahan : experience human development $12^{\text {th }}$ ed). Jakarta : Salemba Humanika
Santrock, J.W. (2011). Masa perkembangan anak buku 2 edisi 11 (terjemahan : child development). Jakarta : Salemba Humanika

Schneiders, A.A. (2008). Personal adjustment and mental health. New York: Holt, Reinhart \& Winston Inc.

Sugiyono. (2010). Metode penelitian kuantitatif kualitatif dan $r \& d$. Bandung: ALFABETA

Thurber, C.A. \& Walton, E.A. (2012). Homesickness and adjustment in university students. Journal of American College Health, 60, 5.

Warsito, L.I.S.S.H. \& Warsito, H. (2013). Perbedaan tingkat kemandirian dan penyesuaian diri mahasiswa perantauan suku batak ditinjau dari jenis kelamin. Jurnal Universitas Negeri Surabaya, 1 (2), 1-6.

Weiten, W. Dunn, D.S. \& Hammer, E.Y. (2012). Psychology applied to modern life : adjustment in the $21^{\text {st }}$ century $10^{\text {th }}$ edition. USA : Linda Schreiber-Ganste 